\title{
From the Perspective of Musical Anthropology to See Fuzhou Tea-picking Opera Music and Cultural Pattern Inheritance Trajectory \\ Bin LV
}

\author{
East China University of Technology, Fuzhou, Jiangxi, China \\ 44675877@qq.com
}

Keywords: Fuzhou tea-picking opera; Music form; Inheritance relations

\begin{abstract}
The tea-picking opera in Fuzhou is one of the most representative operas in the Fuzhou area of Jiangxi Province. Its development reflects the social and cultural changes at that time. This paper draws on the core concept of music anthropology, from the inheritance trajectory of Fuzhou tea-picking opera music culture, to make a comprehensive analysis of Fuzhou tea-picking opera in terms of music, humanities and social sciences and tries to sort out and explore the relationship between music form and cultural background.

Just as the discipline of music anthropology advocating "to regard music as an object and to recognize oneself, one's own society, and the culture that he created from this particular perspective." [1]Sorting out and exploring the historical context of the development of tea-picking in Fuzhou is not only the necessary step to explore its music activity mode, but also is the first condition for mining its cultural connotation. In the current situation of social integration and development, these tracks of art development reflect the specific social and cultural values at each stage.
\end{abstract}

\section{Combing the Development Traceability and Inheritance Relations}

Due to the wide spread of tea-picking opera, music styles vary greatly from place to place, distinguished by local names. As its name implies, Fuzhou tea-picking opera is popular in Fuzhou, Jiangxi Province, is part of a branch of tea-picking opera in Jiangxi Province. Because Fuzhou tea-picking opera has a strong unique drama features, mostly showing content that reflect real life repertoire, and folk feature of singing is flourishing, popular with people.

Fuzhou tea-picking opera, like other traditional folk arts, inherits the living tradition of being people-oriented. It continues the life of folk music directly, comprehensively and exquisitely through opera. It is the unique way of inheritance for this traditional folk art, determining the development situation of Fuzhou tea-picking opera.

In June 2th, 2010, Fuzhou tea-picking opera was included in the third batch of national intangible cultural heritage of the Ministry of Culture. In the following year, Fuzhou Daily issued a report saying that "Fuzhou Tea-picking Opera Has a Terrible Situation, it has a long way to go to protect and inherit it." This report profoundly reflects the fact that the tea-picking drama of Fuzhou is in a state of rapid decline and worrying.

Timothy Rice, a famous national musicologist, mentioned in his four-level target model that the process of music generation is a combination of history, society and individual processes, which are historical, socially maintained for personal use, just as the individual in Fuzhou's tea-picking opera, it refers to the folk old entertainers who are proficient in and engaged in the performing arts of tea-picking in Fuzhou for many years, they are the important links and motives of inheritance.

Fuzhou tea-picking opera's development process can be broadly divided into three stages, namely: three-legged classes, half-time period and the establishment of PRC to now.

Early Stage. The "Chinese Opera Integration · Jiangxi Volume" described earlier Fuzhou tea-picking opera like that: "the forms of a variety of tea-picking, light song content and performance are the same: usually one man and a woman, one man and two women or more than three people to do the performance. The dancers wear color suits, waist ribbons, men usually hold pole, hoe, boat pole and so on, while women hand fancy flower, umbrella or other tea set, singing 
and dancing, the atmosphere is very active. Repertoire: "December Missing Men Tune", "December Tea-picking", "Four Seasons Missing Tune", "Big Ten Embroidered Tune" and so on. [2]

The first art is inseparable from the human productive labor, Fuzhou tea-picking opera is also from the tea-picking songs, tea lights evolved, is accompanied by a plucking tea and singing behavior, the tunes was using a local folk minor, and impacted by Gannan tea-picking drama, performance content and occasions are mostly around tea things.

During this period, the Fuzhou tea-picking opera relied on the continuation of the tea-picking work. The singers interacted and learned in the work, and the musical activities had more practical functions of coordinating and commanding work.

Medium Stage. In the period of Qianlong, Fuzhou was in a period of immigrants and turbulences. There were a large number of refugees living on art in the streets. They brought the Huangmei tea-picking opera in southeastern Hubei Province and performed it in concert with local popular folk songs and tea lanterns Combination of the formation of Fuzhou tea drama prototype three-legged class, that is, once a ugly sitting hall. Because of its small size, performance is also very flexible, usually in restaurants, villagers among the performances, while also recruit apprentice performances, teaching in the continuous summary of the existence of singing, melody, body movements and other issues.

As the show became more and more popular, the performance of the three-legged class performance was not only restricted to the tea business, but also started to describe the music and events in life more. At the same time, its performance form has also been enriched accordingly. On the basis of ugliness, it has formed a real triangle class. This also marks the Fuzhou tea-picking opera as the basic formation of opera art.

Although the story line is not very complete, its appearance led to the development of the dance scene of Fuzhou tea-lamp dance in the form of drama stage performance, and have laid a solid foundation for the brilliant future of the Fuzhou tea-picking drama achievements.

At the end of the Qing Dynasty, Fuzhou Yihuang Opera developed to a certain scale. Some artists in the three-legged class went to study in Yihuang to expand the previous show into the whole play and began to play the robe. Actor acts also increased Sheng, Dan, Chou actress faces. At this time Fuzhou three-legged class began to move toward "half-class" development. [3]

At this Stage. In 1951, Fuzhou local theater group was established, in 1953, officially changed its name to Fuzhou tea-picking group.

In September, 1954, Jiangxi Province held the first drama show, Fuzhou tea-picking group received a number of awards, acclaimed by the opera fans in the province widely, since then, Fuzhou tea-picking opera in the province actively carry out various activities and winning many times. The modern drama "Li Sister remarried" by Fuzhou Tea-picking Troupe was showed in many cities, the "Songs of Red Pine Forest" rehearsed in some counties and cities in the province gained various awards such as creation and music in "Modern Opera Repertoire of Jiangxi Opera". The club drew up nine albums, and the scripts were also published by Jiangxi People's Publishing House, China Drama Publishing House and others. This marks the Fuzhou tea opera in the domestic drama community already has some influence.

From the mid time of 60s in last century, Fuzhou tea-picking show gradually went out of Jiangxi, into the country. In 1962, the traditional drama "The Wrong Boundary" adapted by the Fuzhou Tea Troupe performed in Zhuzhou, Xiangtan, Hunan and other places. In 1965, the East China Modern Opera Observatory was held in Shanghai. The troupe rehearsed the modern opera "Yang" to participate in the observance. It was widely praised and went to Hua Ren Tang in Zhongnanhai to report the performance for the central leadership.

Entering into the 21st century, Fuzhou tea-picking opera is still in full of swing rehearsal, performance, and successfully won the major awards. Such as "County Magistrate Go to the Countryside" and "Mother Love Chicken" won "stars" award of the Ministry of Culture in the 2001 and 2004 annual.

Throughout the history of Fuzhou's tea-picking opera, from the embryonic stage of three people's drama to the well-known local operas, which carry the painstaking efforts of many theatrical 
performers and workers as if they were the solid and constant stone under the majestic bridge across the Yangtze pier, exhausting the life of his life, fulfilled the Fuzhou tea-picking opera career development.

The development of drama history always advances with the development of the times, reflecting the spirit of the times is its bounden duty. The development of tea-picking opera is also dominated by the diachronic development of their inheritance. From the inheritance and development in the productive labor to the inheritance of the folk-custom groups, the inheritance of professional opera and professional colleges and the inheritance of the media network are walking with the development of the times step by step. [4]

\section{Music form Analysis}

The analysis of the main form of music is from three aspects: the singing of tea-picking opera, accompaniment instruments and dramatic image.

Singing Tone. Fuzhou tea-picking opera singing tone went through various periods of development, there are many different categories. According to the comprehensive survey of tea-picking opera in Jiangxi Province of "Chinese Opera Music Integration-Jiangxi Volume", the tone of Fuzhou tea-picking opera is divided into two major categories: main accent and minor accent. One of the main tone is divided into local tone and Chuan tone, minor tone refers to the tea light tone, north and south words, high tone and local minor accent.

The right tune of Opera. Opera tune refers to the board cavity tone, with the local tone, fu tone, single tone, chuan tone the four kinds.

A single tone is the Fuzhou tea-picking opera retains the ancient singing period of the three leg classes, the law is divided into four sentences three rhyme and two rhyme the two kinds, with style (sine) and palace style (anti-string) mainly male and female sing with the same cavity.

The local tone is based on a single tone blending Fengcheng string class and developed, it is the structure of the upper and lower sentence style singing, the sentence is generally 2 or 6 , the next sentence is 5 , male and female with different cavity but not transfer, there are a positive plate (also known as "long rhyme"), Jane plate, stack plate, quick plate, inverted plate, rocking plate, San plate, Qing plate, crying and other plates.

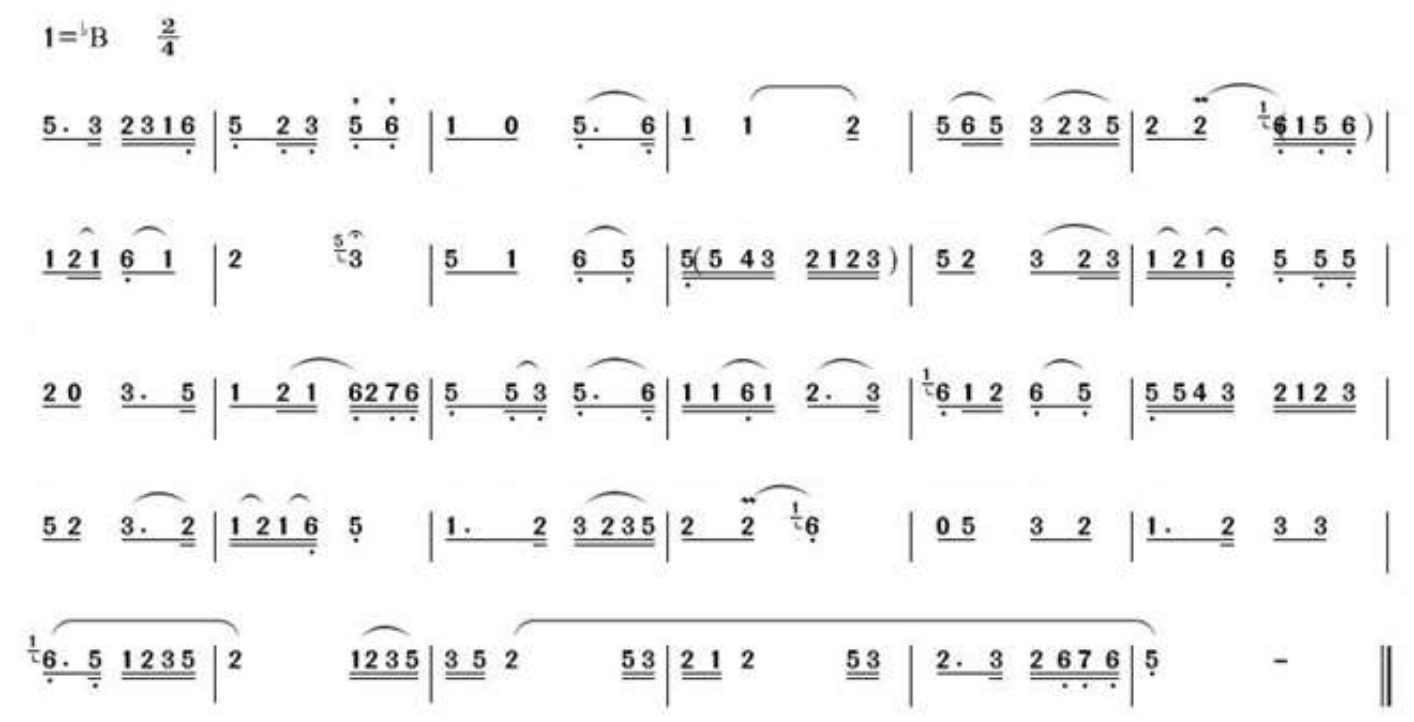

Figure 1.

$\mathrm{Fu}$ tone is made by the local [meet mother tune] Gao Anshi string small flowers and developed, the singing for the palace sentence structure, the next sentence on the sentence falls on 2 or 5 , the next sentence is 1 . There is a distinction between male, female and ugly cavities and, like this one, has a rich plate. 


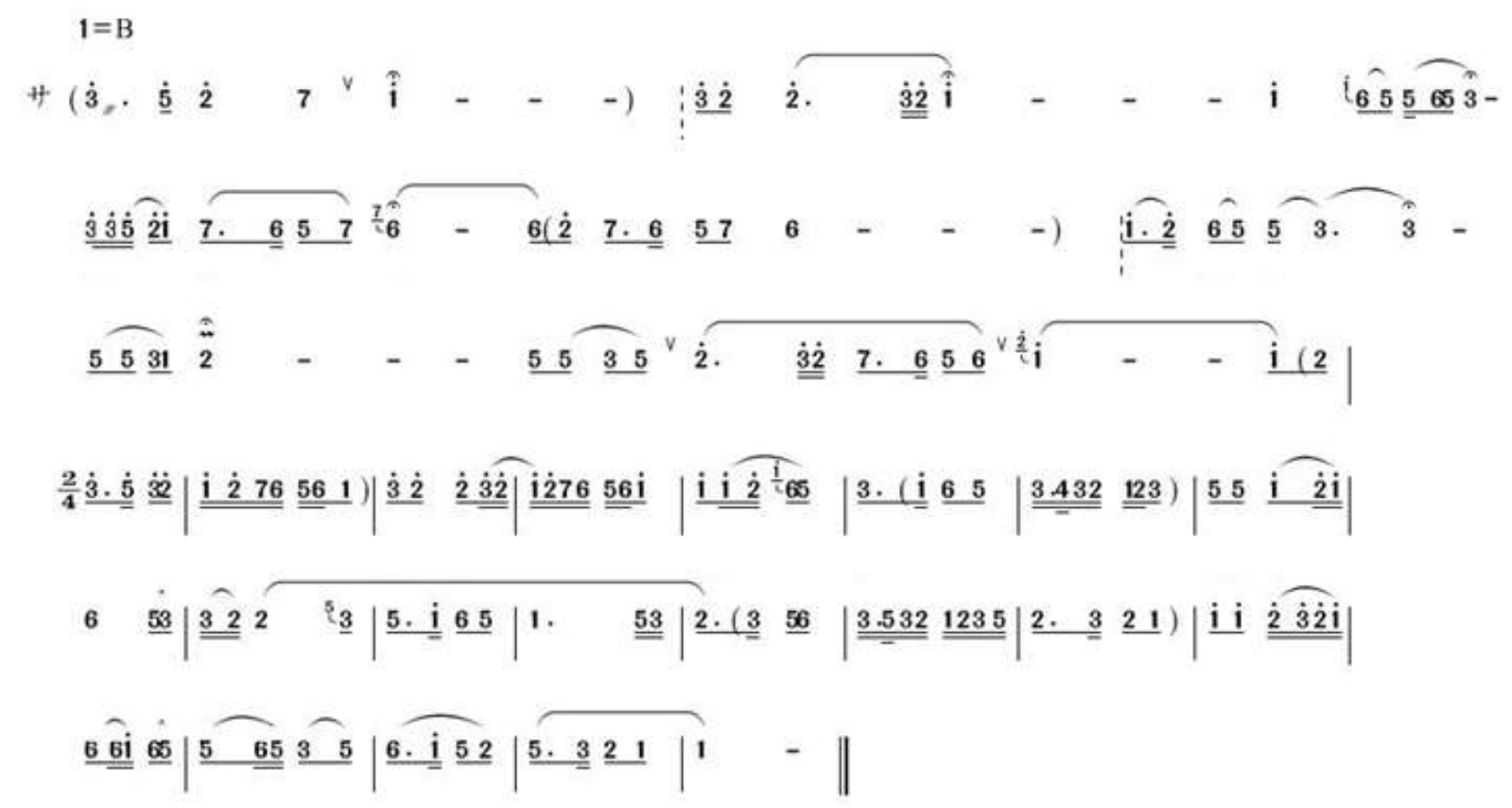

Figure 2.

Chuan transfer is a new tone formed by the integration of foreign tones with the reconciliation and reconciliation. It has two types of reconciliation and palace reconciliation, as well as two types of reconciliation and plume.

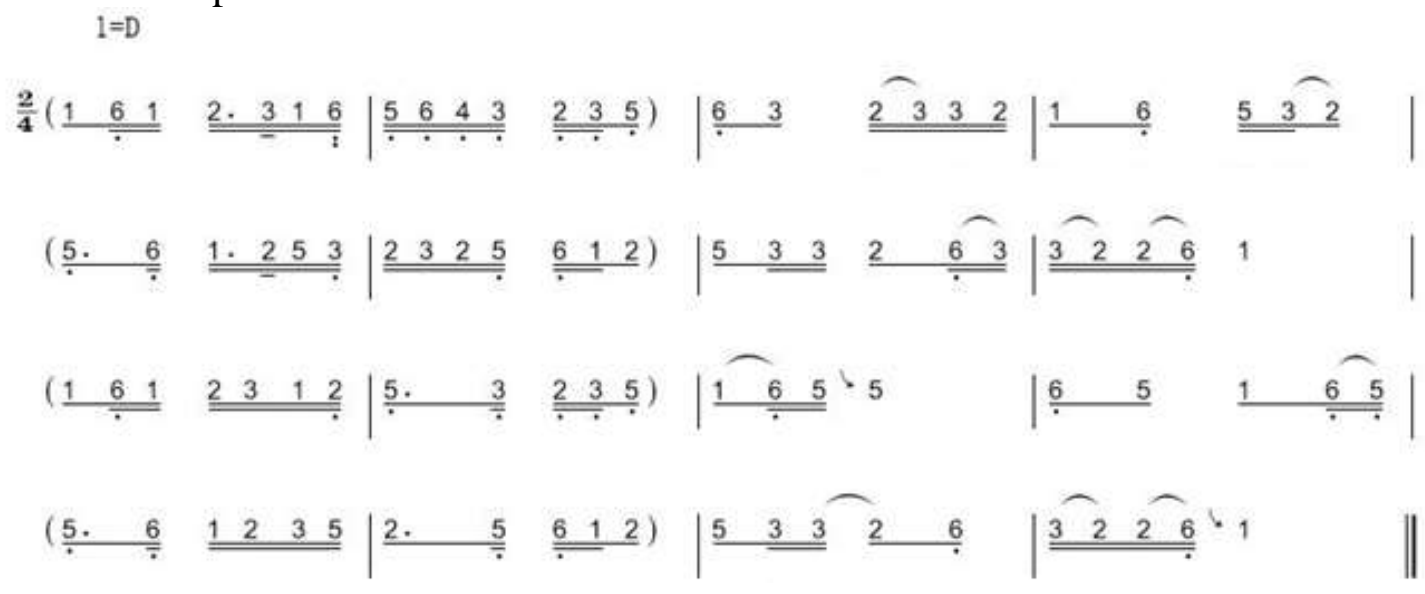

Figure 3.

Drama miscellaneous. Opera miscellaneous was mainly used in the three leg class during a single drama tunes, such as [Tribuluster put cattle transfer], [sell cherry transfer], [double persuaded husband tune], [Wang Mama curse chicken], [fill back tone] and so on, are based on the name of the song for the song. There is also a part of the three leg class to the half-class period from the foreign drama absorbed from the [Southern word], [Northern word], [letter tune] and so on. Besides, it also includes some singing tones.

Folk minor. Minor in folk songs refers to the popular tone in Fuzhou and the minor plays in a single drama, such as "playing a lotus", "wondering", "playing color", "picking tea in December," and " most of the folk songs used in the minor tune style and palace style, and only a few are using angular style and plume style, such as "mining mulberry tune", "bamboo shoots", "a cited" and so on. [5]

Although most of the music of Fuzhou Tea-picking opera follows the principle of same style and one cavity go to the end, many folk songs are stored in the music. These folk songs have great arbitrariness in the style, mode, or the same tune different tonal situation. It is precisely because of 
its arbitrary, do not abide by the characteristics of the program, Fuzhou tea opera demonstrate its unique personality.

Musical Instrument Accompaniment. Fuzhou tea-picking opera has the unique characteristics of the drama, the scale, tone, tonality and spin all have a more fixed general characteristics. Accompaniment instruments based on the style of tea drama is divided into martial arts and the text field. Martial arts often use percussion instruments, while the text field use more Gaohu, erhu, flute and pipa and other musical instruments.

Text field accompaniment instrument.

Pulling the stringed instrument. The earliest Fuzhou tea-picking opera accompanies with the violin only. With the development of the tea-picking opera, the types of stringed instruments gradually increase. Fuzhou Tea-picking Troupe adopts two different styles of Gao Hu (with GD and FC strings) And bass huqin, to expand its range, the sound is also more vigorous.

In performance, the G-D string of tall beard were called the big cylinder, usually used to play recital; F-C Ching Gao $\mathrm{Hu}$ is called a small cylinder, to play the palace-style singing. In order to harmonize the range, the pitch of the tall Hu's inner string is respectively the outer string pitch of the erhu and the bass huqin, namely: $\mathrm{C}-\mathrm{G}$ and $\mathrm{B}-\mathrm{F}$ respectively.

Plucked instruments. At present, Fuzhou tea-picking troupe uses plucked instruments only the pipa. For some time, it used the Yueqin instrument. However, because of its narrower range than the pipa, its use is too limited and gradually abandoned. Now pipa being used has the four-string four-column, five-degree set, respectively, G-C-D-G.

Wind instruments. The wind instruments are flutes and suona. The flutes are usually used as the main melody instrument in the tea-picking opera and play a decisive role in the band. The commonly used tone has a positive tone $(1=\mathrm{G})$, where the Fan tone $(1=b \quad$ E), the up tone $(1=$ b B), Chizi tone (1=C), Six word tone $(1=F)$ and so on.

General indoor performances do not have suona, but only used in some weddings and funerals special occasions.

Martial arts accompaniment instruments. The martial arts accompaniment instrument is mainly percussion instruments. The Fuzhou tea-picking drama follows the local traditional lanterns and the folk drums, drums, soil coins, small rubs and gongs, etc. It also absorbs the performance of the Beijing Opera percussion, some percussion instruments, such as those used in the drums and gongs, add atmosphere to the fight scenes in the martial arts field.

Drama Image. Drama is a common social and cultural phenomenon in human history. It shows both the symbol of the system of human nature construction and the vivid life.

Starting from the distance, and finally unity. Chinese opera is an integrated form of stage performance. Fuzhou tea-picking drama was conceived in the talented village-Fuzhou, its profound cultural heritage goes without saying. Tea-picking plays are closely linked with the local culture. The coordination of roles with music, stage, costume, etc. always follows the principle of beauty.

From the shape to get meaning, proud and forget shape. "Art comes from life and is higher than life." This sentence brilliantly summarizes the source of all art. Fuzhou tea-picking drama is good at representing small incidents in daily life. Using the power of niche Xia Dan and dwarf steps of the clown, Fuzhou Tea-picking Theater vividly portrays a small picture of people's lives and narrows the gap between the art of opera and the people, in order to obtain enduring development.

Stage is a small world, world is a big stage. Li Diaoyuan, a famous opera theorist in Qing Dynasty, once proposed that "opera is also non-opera; This is actually a very common view of the Chinese people about the relationship between "opera" and social life. They think that "drama" has always happened to us and "life is always in play." The "play" in "Stage of Little World" is merely the miniaturization and artistry of all kinds of hues of "big stage of world". [6]

\section{Cultural Interpretation and Social Maintenance}

Clifford Geertz, the famous anthropologist of contemporary interpretation, argued that "the description of the phenomenon of human social activities can not stop at the accumulation of 
institutional material, but should constitute a kind of 'deep description' that stands in one 'different culture' of the anthropologist's own culture." [7]From this passage, we can see that Geertz's research attitude towards "different cultures "is" to understand others' understanding, " that is to say, the study of his culture must be based on the perception of his cultural groups over their own culture.

When we enter an alien cultural circle, we should objectively describe the local cultural phenomenon as an "outsider" and then convert it into an "insider" after we understand the local people's view of their life style. Then, as we saw in the classical times, completely drilled into the minds of local people, "explaining the phenomenon of their cultural activities with local people's evaluation criteria of cultural identity.

For how to understand the local people's cultural values, Gerdz argues that "to understand a nation's culture is to show its normality and place them in their daily system without undermining its particularity, then they become understandable." [8]

Fuzhou tea-picking opera is not only inherited the national culture, but also a mirror of social changes in history. If we can see the social background of the Fuzhou tea-picking opera nowadays, it is not hard to explain why the wonderful work in this Chinese opera dwindles day by day. The cruel imprisonment of the Cultural Revolution on the arts and culture during the Cultural Revolution of 10 years and the drastic social and economic development after the reform and opening up have brought about tremendous changes in these social environments.

As a carrier of national culture, the inheritance and development of the tea-picking opera in Fuzhou reflects the national spirit, national character, national psychology, moral values and values of this region and integrates with the national psychology, culture and customs. In the inheritance and change of Fuzhou tea-picking process, it blends local people's religious beliefs, customs and social and cultural characteristics.

Music is one of the important carriers and manifestations of culture. Folk music, as an important part of the cultural phenomenon, shows its unique charm in the long cultural history of China.

I remembered Mr. Wu Wenzao explained "culture" in the following way: "Culture is the core of community research. The simplest definition of culture can be said to be a lifestyle formed by residents of a certain community. The lifestyle refers to a certain structure formed by the activities of residents in all aspects of their life, culture can also be said that the total score of nation to deal with the environment - physical, conceptual, social and spiritual environment"[9]

The culture of every nation can be manifested in its current life. The natural environment, ways of living and behavior of living in each nation belong to the category of national culture. The cultural style showed in Fuzhou tea-picking opera has an inextricable link with Fuzhou local economy and life history.

The inheritance of traditional opera art should also pay attention to carrying forward the new culture in the new era. Nowadays, as the successors are getting old, but there is no successor, it has caused great difficulties both in tracing the source of the musical form of tea-picking in Fuzhou and in sorting out the context of its inheritance. [10]

The development of folk music needs the continuity of inheritance, and the protection of folk heritage is also an important means for the global intangible cultural heritage. Although the tea-picking opera in Fuzhou has received the attention of the whole province and even the whole country, the work done in recent years has not been able to take effective measures to promote the development of the tea-picking opera in Fuzhou. This work still needs the vigorous support and unremitting perseverance of the relevant government departments in order to truly achieve the purpose of protecting the folk cultural heritage.

\section{Acknowledgements}

This article is stage results of the 2015 Jiangxi Province Humanities and Social Science Research Project "Music Anthropology Dimension Fuzhou Tea-picking Musical Form Research", project number: YS1501. Author: East China University of Technology 


\section{References}

[1] Luo Qin. "Theory and Methodology of Musical Anthropology" [M]. Shanghai: Shanghai Conservatory of Music Press.2011

[2] China National Folk Literature and Art Editorial Board. Chinese Opera - Jiangxi Volume [M]. Beijing: China ISBN Center. 2014

[3] Fei Xiaotong, Wang Tonghui. "Flower Basket Yao Social Organization" [M]. Nanjing: Jiangsu People's Publishing House. 2015

[4] Gu Jianguang. "Culture and Behavior" [M]. Sichuan: Sichuan People's Publishing House.2015

[5] Guan Jianhua. "Musical Anthropology Horizon - music research from the global cultural perspective" [M]. Shanghai: Shanghai Conservatory of Music Press. 2010

[6] Zhongjing Wen. "Introduction to Folklore" [M]. Shanghai: Shanghai Literature and Art Publishing House. 2016

[7] Clifford Geertz. "Cultural Interpretation" [M] Han Li translation. Nanjing: Yilin Press.2012

[8] Wang Ming. "Gerdz's interpretation of anthropology" [J]. Teaching and Research. 2014, 4

[9] Xu Ping. "Cultural Adaptation and Change" [M]. Shanghai: Shanghai People's Publishing House. 2016

[10]Zhou Wenzhong and Deng Qiyao. "Self-propagation, Protection and Development of Ethnic Cultures" [J]. Thought Front, Journal of Humanities and Social Sciences, Yunnan University, 2013,1 